\title{
Tin-free Radical Allylation of $\alpha$-Acetoxy Alkyl Xanthates. Routes to Homoallyl Alcohols and $\alpha, \beta$-Unsaturated Ketones
}

\author{
Jin Young Lee and Sunggak Kim \\ Center for Molecular Design \& Synthesis and Department of Chemisty, School of Molecular Science (BK-2I), \\ Korea Advanced Institute of Science and Technology, Daejeon 305-701, Korea. "E-mail skim(i)kaistac:kr \\ Received November 7, 2005
}

Key Words : Radical reaction, $\Lambda$ llylation, I Jomoallyl alcohol, $\alpha, \beta$-Unsaturated ketone

Radical allylations are most frequently used intermoleculat radical carbon-carbon bond forming reactions and provide an easy access to introduce allyl groups into organic molecules under mild conditions.' Allylating agents normally utilize simple allyl and 2-substituted allyl stanmanes along with the corresponding sulfides and sultones. Contrary to the tadical allylations, radical-mediated aldol reactions have not been well developed due to the very high $\pi$-bond strength of $\mathrm{C}-\mathrm{O}$ bonds. Thus, several indirect approaches for aldol-type products have been reported to datc:-? We studied the possibility of indirect radicalmediated aldol reactions using $\alpha$-acetoxy alkyl radicals along with reagent equivalents of the $\alpha$-ketone acceptor synthon. In this regard, 2-acetoxy and 2-benzoyloxy substituted allyl sulfones seemed to be promising for our purpose. ${ }^{\circ}$ The combination of these new allylating agents together with the $\alpha$-acetoxy alkyl radical precursors would provide $\alpha, \beta$-unsaturated ketones after hydrolysis of the acetates and the lollowing dehydration.

Among several $\alpha$-alkoxy alkyl radical precursors, $\alpha$ bromoalkyl acetate 1 seemed to be most attraclive and promising to introduce an acetate group at the $\beta$-position of an alkenyl bond. "Previously, radical allylation of 1 with allyl stannane was known to give a homoallyl acetate. ${ }^{10}$ Furthermore, chiral $\alpha$-alkoxy alkyl radicals were generated from decarboxylation of $\alpha$-alkoxy substituted Barton esters. ${ }^{5}$ The $a$-bromoalkyl acestate 1 was readily prepared by the addition of acetyl bromide to an aldehyde in the presence of zinc chloride in methylene chloride al $0^{\circ} \mathrm{C}$ (cq. 1). ${ }^{11}$

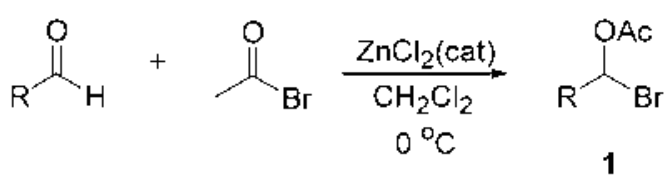

Sinee $\alpha$-bromoacetates were unstable to aqueous workup, the crude $\alpha$-bromoacetate 1 was used for the radical allylation reactions without purification. Irradiation of a

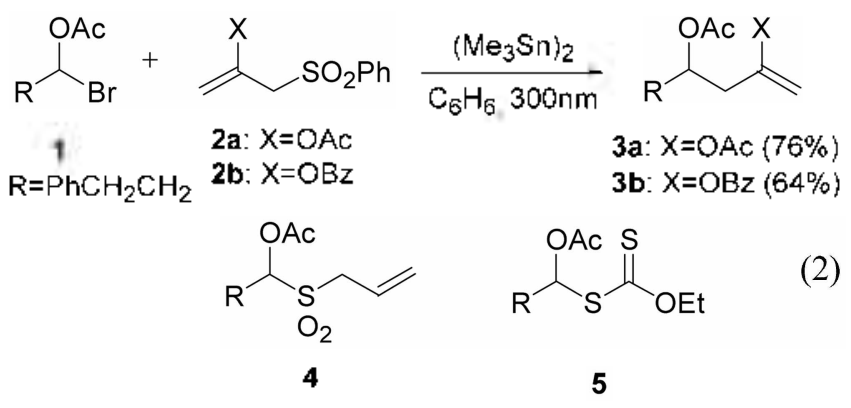

solution of 1 and 2-acetoxyallyl phenyl sulfone (2a) in benzene at $300 \mathrm{~mm}$ for $9 \mathrm{~h}$ afforded the desired allylation product $3 a$ in $76 \%$ yicld (eq. 2). $\Lambda$ similar result was oblained with $2 \mathrm{~b}$, yielding $3 \mathrm{~b}$ in $64 \%$ yicld under the same condition.

In order to achicve tin-free radical allylation, ${ }^{12}$ we initially attempted to prepare allyl sulfone 4 by the reaction of 1 with sodium salt of allyl mereaptan and the subsequent oxidation to $4 .^{13}$ I Iowever, when 1 was treated with sodium salt of allyl mercaptan in DMF at room temperature, the corresponding aldehyde was obtained, indicating that the allyl mercaptan anion reacted with the acetate group. Thus, our nex1 attention was given to the xanthate precursor. ${ }^{1-4}$ Treatment of 1 with potassium $O$-ethyl xanthati in acelone at room temperature to aflord $\alpha$-acetoxy xanthates 5 in good yiclds. The xanthates 5 were thermally and hydrolytically very slable. Furthemore, 2-acetoxy and 2-benzoyloxy allyl ethyl sulfone ( 9 a and 9 b) were prepared by treatment of proparsyl ethyl sulfonc with acetic acid and benzoc acid, respeclively.

We initially studied tin-liee allylation using a xanthate precursor and an allyl ethyl sullone aceptor (Seheme 1). Reaction of xanthate 5 with elhyl allyl sulfone 6a using lauroyl peroxide as initiator in dichlorocthane at $90^{\circ} \mathrm{C}$. for 6 $\mathrm{h}$ allorded homoallyl acelate $7 \mathrm{a}$ in $83 \%$ yield. Hydrolysis of 7a with $0.1 \mathrm{~N} \mathrm{NaOH}$ in acelonitrile for $9 \mathrm{~h}$ afforded $8 \mathbf{a}$ in

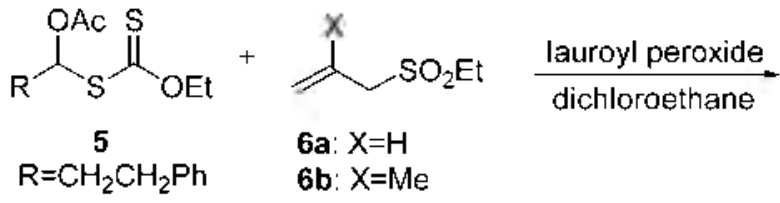

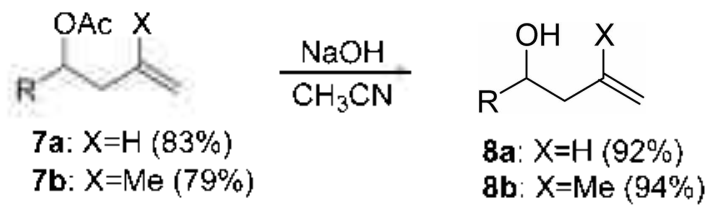

Scheme 1. Preparation of homoallylic alcohol 8 from 5 and 6. 


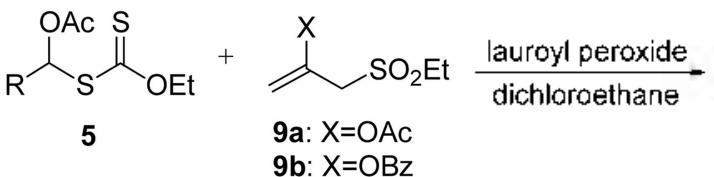

9a: $X=O A c$
9b: $X=O B z$

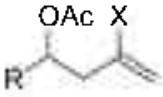

3a: $X=O A C$

3b: $X=O B z$
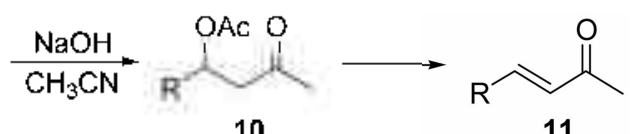

11

Scheme 2. Preparation of $\alpha, \beta$-unsaturated ketone 11 from 5 and 9.

Table 1. Tin-free Allylation of $\mathbf{5}$ with Allyl Sulfone 9 and Ilydrolysis of 3 to $11^{\text {tt }}$

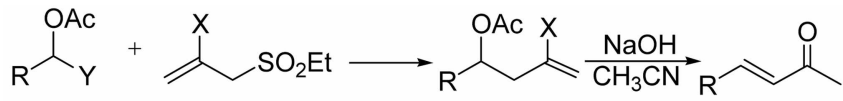

$$
\begin{aligned}
& 59 \\
& Y=S C(S) O E t \text { 9a: } X=O A C \\
& \text { 9b: } X=O B z
\end{aligned}
$$

allylation approaches to $\alpha, \beta$-unsaturated ketones using $\alpha$ aceloxy alkyl xanthates 5 as radical precursors and 2acetoxy and 2-benzoyloxy allyl ethyl sulfone as radical acceptors.

Acknowledgment. We thank CMDS and BK21 project for financial support.

\section{References}

I. For reviews, see: (a) Curran, D. I. Synhesis 1988, 489. (b) Rosenstein. I. J. In Rodicals in Organic Sinthesis; Renaud, P.; Sibi, M. P., Fds: Wilcy-VCl I: Weinheim, Germany. 200I; Vol. I, p 50 .

2. (a) Keck, (j. E.: Enholm, E. J.; Yales, J. B.; Wiley, M. R. Tetrahedron 1985, 11, 4079. (b) Mizuno, K.: Ikeda, M.; Toda, S.: Otsuii, Y. J. Am. Chem. Soc. 1988, 110, 1288. (c) Miura, K.; Itoh. D.; Hondo. T.; Saito. H.; Ito, H.; Hosomi, A. Tetrahedron Lett. 1996. 37.8539 .

3. (a) Keck, (i. E.; Byers, J. H. J. Org. Chem 1985, 50, 5442. (b) Curran, D. P.; Yoo, B. Tetrahedron Lett. 1992, 33,6931.

4. (a) Leno, Y.; Aoki. S.; Okawara, M. $J$. Chem. Soc., Chem. Commm. 1980, 683. (b) Smith. T. A. K.: Whitham, G. H. Chem. Commm. 1985, 897. (c) Padwa, A.; Kline, D. V.; Murphree, S. S.; Yeske, P. [., J. Org. Chem, 1992, 57, 298. (d) Chatuiljaloglu, C.; Alberti, A.; Ballestri, M.. Macciantelli, D. Tetrahedron Lett. 1996, 37.6391 .

5. (a) Garner, R?; Leslie, R.; Anderson, J. T. J. Org. Chem. 1996, 61 . 6754. (b) Garner. P.; Anderson, J. T. Org. Lett. 1999, /, 1057. (c) Garner, P.: Anderson. J. T.; Cox, P. B.; Klippenstein, S. J.; Leslie, R.; Scardovi, N. J. Org. Chem, 2002, 67,6195.

6. (a) Lee, E.; Tac, I. S.; Lee. C.; Park. (. M. Tetrohedron Lett. 1993, 34. 4831. (b) Lee, E.; Yoo, S. K.; Choo, Il.; Song, HI. Y. Tetrahedron Lett. 1998, 39, 317.

7. (a) Sibi, M. P.: Zimmerman, I.; Rheault, T. Angent: Chem. Int Ed. 2003, 42, 4521. (b) Sibi. M. P?; Patil, K. Org. Lett. 2005, 7, 1453 .

8. (a) Appleyard, (i. D.; Stirling, C. I. M. .. Chem. Soc., Chen. Commen. 1967, 2686. (b) Ileno, Y; Ohta, M.; Okawara. M. .I Organomet. Chem. 1980, 197, Cl.

9. Chou, T. S.; Knochel. P. J. Org. Chem. 1990, 55, 4791.

10. Sun, S.: Curran, D. P. Tetrohedron Len. 1991, 32, 6097.

11. (a) Veuenschwander, M.; Bigler, P; Christen, K; Iseli, R; Kyburs. R.: Muble. H. Hotv Chim. Acta 1978, 61, 2047. (b) Knochel, P.; Chou. T. S.; Juber, C.; Rajagopal, D. J. Org. Chem. $1993,58,588$.

12. For our previous reports on tin-free radical reactions, see (a) Kim, S.; Lim, C. J. Angew: Chem. Int Ed 2002, 41, 3265, (b) Kim, S.; I.im, C. 1. Butl Korean Chen Sot 2003, 24, 1219. (c) Kin, S. Lee, S.; Lim, C. J. Bull. Korean (hem. Soc: 2004, 25, 1611. (d) Kim. S.: Kim, S.; Otsuka, $N_{\text {.; }}$ Ryu, I. Angew: Chem. 2005, 17 , 6339.

13. (a) Quiclet-Sire, B.: Zard, S. Z. J. Am. Chem. Soc: 1996, //8, 1209. (b) Bertrand. F.: Ouiclet-Sire, B.: Seguin. S.; Zard. S. Z. J. An. Chem. Sor: 1997, 119,7410.

14. 7ard, S. 7. Angew: (hem. Int. Ed. 1997, 36, 672. (b) Forbes, J. E.; Zard, S. Z. J. An Chem. Soc. 1990, 112,2034 . (c) Sire, B.; Seguin, S.; Lard, S. L. Angew: Chom. Int. Ed. 1998, 37, 2864. 